\title{
Pancreatitis in Systemic Lupus Erythematosus - Case Series from a Tertiary Care Center in South India
}

\author{
Ruchika Goel $^{1}$, Debashish Danda ${ }^{*}$, , John Mathew ${ }^{1}$ and Ashok Chacko ${ }^{2}$ \\ Department of Clinical Immunology and Rheumatology ${ }^{I}$ and Department of Gastrointestinal Sciences ${ }^{2}$, Christian \\ Medical College \& Hospital, Vellore-632004, Tamil Nadu, India
}

\begin{abstract}
Pancreatitis in Systemic Lupus Erythematosus (SLE) is a rare, but life threatening complication. We aimed to study the characteristics and treatment outcome of SLE patients with acute pancreatitis in comparison with those with abdominal pain due to causes other than pancreatitis. Records of SLE patients admitted in our ward with pain abdomen between January 2008 and July 2010 were studied retrospectively. Of 551 SLE in-patients during the study period, 28 (5\%) had abdominal pain and $11(2 \%)$ of them were diagnosed to have acute pancreatitis. Five of the 11 patients had severe pancreatitis and 6 had mild pancreatitis. Seizures, arthritis and lack of prior use of steroids were significantly more common in patients with pancreatitis as compared to those with abdominal pain of non pancreatic origin. Seizure occurred more often in severe pancreatitis group as compared to mild pancreatitis. There was no difference in prevalence of lupus anticoagulant and anticardiolipin antibody (40\%) between SLE patients with pancreatitis and those with other causes of abdominal pain. Conclusion: Association of pancreatitis in our cohort of SLE patients include withdrawal of maintenance dose of steroids, seizures and arthritis in univariate analysis. However there was no independent predictor of this complication in our study.
\end{abstract}

Keywords: Systemic lupus erythematosus, pancreatitis, abdominal pain.

\section{INTRODUCTION}

Pancreatitis in systemic lupus erythematosus (SLE) is a rare but serious complication. Less than 200 cases have been reported in literature with an annual incidence of 2.3/1000 SLE patients $[1,2]$. We report our experience on profile and treatment outcome of SLE patients with acute pancreatitis and a comparison of these with patients presenting with abdominal pain due to causes other than pancreatitis.

\section{PATIENTS AND METHODS}

Records of SLE inpatients admitted with pain abdomen between 2008 to 2010 were studied retrospectively. All patients had fulfilled ACR 1997 revised classification criteria [3]. Details of demography, clinical features, SLE disease activity assessment (SELENA SLEDAI), laboratory parameters, imaging studies and management were noted [4]. Patients were categorized into those with abdominal pain due to pancreatitis and those with pain of non pancreatic etiology. Diagnosis of acute pancreatitis was made in the presence of abdominal pain or tenderness characteristic of pancreatitis, with at least 2 fold elevation of serum pancreatic enzymes i.e. serum amylase or lipase with or without imaging features [5]. Those with pancreatitis were further sub-classified into mild and severe subsets using Atlanta criteria, 1992 [6].

Data was analyzed using SPSS-version 15. Fischer's exact test was used to compare the two groups. The $p$ value of $<0.05$ was considered statistically significant.

*Address correspondence to this author at the Department of Clinical Immunology \& Rheumatology, Christian Medical College \& Hospital, Vellore632004, Tamil Nadu, India;

Tel: 914162282529; Fax: 91-416-2232035;

E-mails: debashisdandacmc@hotmail.com,debashish.danda@cmcvellore.ac.in

\section{RESULTS}

Among 551 SLE patients admitted during the study period (data retrieved from our SLE database), 28 (5\%) had presented with abdominal pain and $11(2 \%)$ of them were diagnosed to have acute pancreatitis. Five of these 11 patients had severe pancreatitis and 6 had mild pancreatitis.

Causes of abdominal pain of non pancreatitis origin included mesenteric ischemia, diagnosed clinically by characteristic abdominal pain and normal pancreatic enzymes in 1, probable intestinal vasculitis in 2, blood culture proven septicemia in 1, post surgery subacute obstruction due to intestinal adhesions in 1, acute gastroenteritis in 1 and no identifiable causes in 11 patients. Pancreatitis was ruled out in these 17 patients by absence of characteristic abdominal pain and/or by lack of elevated levels of pancreatic enzymes which were measured in 8 out of these 17 patients.

Majority of patients were females (26/28) and mean age was $26.7 \pm 6.7$ years. The median disease duration of SLE in patients with pancreatitis was 12 (range 2 - 72) months. None of the patients with pancreatitis had history of diabetes, alcoholism and cholelithiasis. Serum calcium and triglyceride levels were measured in $8 / 11$ and $6 / 11$ patients with pancreatitis respectively, but none of them had hypercalcemia or triglyceride levels more than $500 \mathrm{mg} / \mathrm{dl}$. No patient with pancreatitis was on azathioprine within the preceding 3 months.

A comparison of salient clinical features and lab parameters of patients with pancreatic and non pancreatic abdominal pain is listed in Table $\mathbf{1}$. 
Table 1. A Comparison of Salient Clinical Features and Lab Parameters of Patients

\begin{tabular}{|c|c|c|}
\hline Parameters & Abdominal Pain of Non Pancreatic Origin & Abdominal Pain Due to Pancreatitis \\
\hline \hline Cutaneous involvement & $3 / 17$ & $6 / 11$ \\
\hline Articular involvement & $4 / 17$ & $4 / 11 *$ \\
\hline Serositis (pleural/pericardial effusion) & $3 / 17$ & $6 / 11 *$ \\
\hline GTCS & $0 / 17$ & $0 / 11$ \\
\hline Psychosis & $1 / 17$ & $11 / 11$ \\
\hline Anemia & $16 / 17$ & $3 / 11$ \\
\hline Leucopenia (WBC count $<4000 / \mathrm{mm} 3)$ & $4 / 17$ & $2 / 11$ \\
\hline Proteinuria $(24$ hr urine protein $>500 \mathrm{mg})$ & $4 / 17$ & $4 / 10$ \\
\hline Elevated creatinine $(>1.4 \mathrm{mg} / \mathrm{dl})$ & $11 / 15$ & $5 / 11$ \\
\hline Low C3 $(<90 \mathrm{mg} / \mathrm{dl})$ & $1 / 11$ & $11 / 11$ \\
\hline Low C4 $(<10 \mathrm{mg} / \mathrm{dl})$ & $11 / 15$ & $10 / 11$ \\
\hline Positive LA by dRVVT test & $8 / 15$ & $4 / 10$ \\
\hline Positive aCLA $(>12 \mathrm{U} / \mathrm{ml})$ & $7 / 8$ & $4 / 10$ \\
\hline Mean SLEDAI & $6 / 13$ & $22 \pm 11$ \\
\hline
\end{tabular}

GTCS: generalized tonic clonic seizure, LA: lupus anticoagulant, ACLA : anticardiolipin antibody. $* \mathrm{p}<0.05$.

\section{DISCUSSION}

Articular involvement and occurrence of generalized tonic clonic seizures were significantly more common in patients with pancreatitis. This could be explained by high SLE disease activity in these patients. Other factors contributing to higher frequency of seizures in these patients could be electrolyte imbalance, antiphospholipid antibody syndrome or renal failure. Though $40 \%$ of our SLE patients with pancreatitis tested positive for antiphospholipid antibodies i.e. Lupus anticoagulant (LA) or Anticardiolipin antibody (aCLA), this frequency was not significantly different from that in patients with abdominal pain of non pancreatic origin, similar to that reported in earlier series [7]. None of our patients with pancreatitis had psychosis and only one had skin rash suggestive of cutaneous vasculitis, which was less frequent than reported incidence in series by Makol et al., [7].

Lack or withdrawal of prior steroid usage was also significantly associated with pancreatitis $(7 / 11 v s 4 / 17, \mathrm{p}<0.05)$ in our series. Moreover, withdrawl of low dose maintenance steroid therapy was more often seen in severe as compared to mild pancreatitis $(4 / 6 v s 0 / 5, \mathrm{p}=0.061)$. These associations could again reflect relapse of disease activity due to suboptimal therapy. The association of high SLE disease activity with bad outcome in pancreatitis has already been reported in a previous study [8].

A multivariate analysis was done for independent predictors for pancreatitis, using the above three items found significant in univariate analysis and it did not reveal any significance probably due to smaller number of patients. Once pancreatitis was diagnosed, all our patients were treated with high dose steroids irrespective of severity status of pancreatitis. One patient was given anticoagulation in addition, due to moderately positive lupus anticoagulant and deep vein thrombosis.

Four patients (36\%) had adverse outcome in the form of fatality in 2 and multiorgan dysfunction requiring ventilatory support in the remaining two. This figure is higher than that in other studies, which could possibly be explained by higher infection rate in our patients $[2,7,9]$.

In summary, pancreatitis was rare $(2 \%)$ in our cohort of inpatients with SLE. Seizures, arthritis and discontinuation of maintenance dose of steroids were significantly more common in patients with pancreatitis, when compared to those with abdominal pain of non pancreatic origin. Occurrence of seizure went hand in hand with severity of pancreatitis. Forty percent of SLE patients with pancreatitis had antiphospholipid antibodies, similar to that in SLE patients with other causes of abdominal pain.

\section{ACKNOWLEDGEMENT}

Declared none.

\section{CONFLICT OF INTEREST}

Declared none.

\section{REFERENCES}

[1] Tian XP, Zhang X. Gastrointestinal involvement in systemic lupus erythematosus: Insight into pathogenesis, diagnosis and treatment. World J Gastroenterol 2010; 16(24): 2971-7.

[2] Pascual-Ramos V, Duarte-Rojo A, Villa AR, et al. Systemic lupus erythematosus as a cause and prognostic factor of acute pancreatitis. J Rheumatol 2004; 31(4): 707-12.

[3] Hochberg MC. Updating the American College of Rheumatology revised criteria for the classification of systemic lupus erythematosus. Arthritis Rheum 1997; 40(9): 1725.

[4] Petri M, Kim MY, Kalunian KC, et al. Combined oral contraceptives in women with systemic lupus erythematosus. N Engl J Med 2005; 353(24): 2550-8.

[5] Kiriyama S, Gabata T, Takada T, et al. New diagnostic criteria of acute pancreatitis. J Hepatobiliary Pancreat Sci 2010; 17 (1): 24-36.

[6] Bradley EL, 3rd. A clinically based classification system for acute pancreatitis. Summary of the International Symposium on Acute Pancreatitis, Atlanta, Ga, September 11 through 13, 1992. Arch Surg 1993; 128(5): 586-90.

[7] Makol A, Petri M. Pancreatitis in systemic lupus erythematosus: frequency and associated factors - a review of the Hopkins Lupus Cohort. J Rheumatol 2010; 37(2): 341-5. 
[8] Wang CH, Yao TC, Huang YL, Ou LS, Yeh KW, Huang JL. Acute pancreatitis in pediatric and adult-onset systemic lupus erythematosus: a comparison and review of the literature. Lupus 2011; 20(5): 443-52.
[9] Dhir V, Misra R, Agarwal V, Lawrence A, Aggarwal A. Lupus pancreatitis - early manifestation of active disease. Lupus 2011; 20(5): $547-8$.

(C) Goel et al.; Licensee Bentham Open.

This is an open access article licensed under the terms of the Creative Commons Attribution Non-Commercial License (http://creativecommons.org/licenses/by-nc/3.0/) which permits unrestricted, non-commercial use, distribution and reproduction in any medium, provided the work is properly cited. 